\title{
GALERÍA \\ DE ARTES VISUALES
}

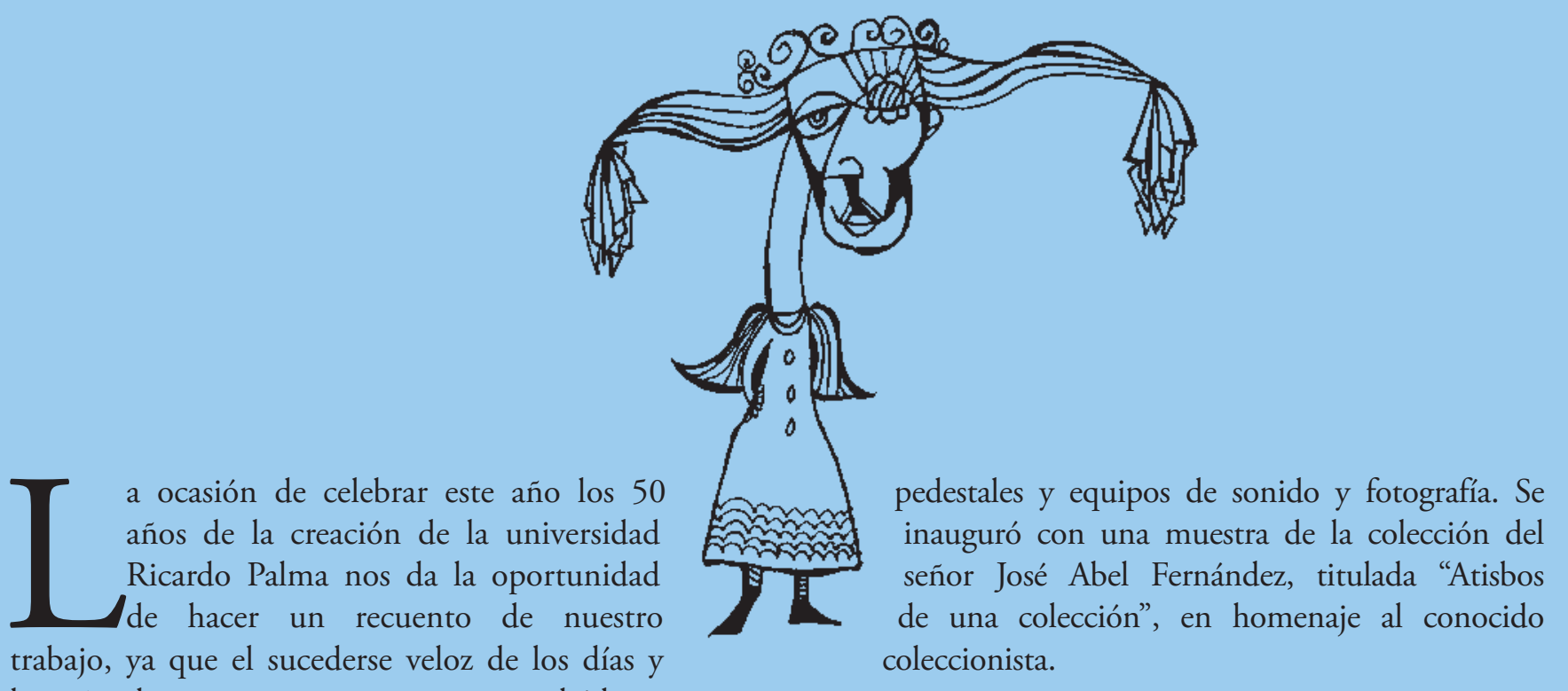

los años hacen, que a veces, que nos olvidemos de preguntarnos si hemos avanzado o no. En lo que se refiere a la Galería de Artes Visuales, a mi cargo, es saludable hacer memoria de su desarrollo desde los días de su creación en el campus universitario en 1997, en los espacios que hoy ocupa el Museo de Historia Natural Dra. Aleman. Era un lugar poco apto para albergar una galería de arte, ya que estaba rodeado de ventanas y persianas; hay que agregar que la iluminación eléctrica proveniente de dicroicos era deficiente y costosa. Sin embargo en este local, y asistidos siempre por la Oficina de Mantenimiento de nuestra universidad, se inauguró con la exposición " 5 más 5", muestra que reunió a cinco críticos y cinco artistas plásticos. Otra exposición que se recuerda con agrado por lo novedosa fue "El lápiz bien temperado" que reunió a las artistas gráficos del 60 . Inolvidables fueron "Maestros del carrizo", en las que se utilizó la caña o zacuara para hacer, con la ayuda de los maestros pirotécnicos, los animales que acompañan las fiestas populares. A parte de lo novedoso, sirvió para dar a conocer al público un capítulo desconocido de la Historia del Arte Popular antes negado.

En el año 2005 la Galería de Artes Visuales se trasladó al Ccori Wasi, casona antigua ubicada en Miraflores, que fue remodelada por los arquitectos Juvenal Baracco y Enrique Bonilla. Desde la época de su inauguración ha sido equipada, poco a poco, de un equipo de luces modernas,

A continuación de las más representativas:

Exposición colectiva " $5+5$ " (1997).

- Segundo Festival de Video/Arte/Electrónica. (1998)

- "Mirada intrusa. Colectiva Fotográfica de NO fotógrafos" (2000);

- "El lápiz bien temperado. Diseño gráfico de la década del 60" (2001); "Atisbos de una colección" de José Abel Fernández (2005)

- "Huellas y sombras", de la artista conceptual brasileña Regina Silveira (2006). "La imagen develada 1961-1979“, grabados de Alberto Quintanilla (2007)

- Danza, mitos, ritos, visiones señales" de Luis Arias Vera (2008) "Panacas reales" de Víctor Escalante (2009)

- "La selva invisible" Bruce Rubio (2010)

- "Las edades del hombre" José Luis Carranza (2010) "Dioses y hombres de los Andes" de Josué Sánchez (2014) "Exposición Antológica" de Charo Noriega (2014) "Ausencia del silencio" Adolfo Asmat (2016)

- "Manufactura" de Andrés Ennen, (2016)

- "Ya Vengo" del arquitecto Elio Martuccelli (2017)

- "Amentes" colección del hospital Víctor Larco Herrera (2018) "Ciudad Cansada" del artista Nelson Flores (2018) "Descifrando un espejismo" de la artista Maroe Susti (2018) "10 años de Xilografía" del artista Luis Torres Villar (2018) 


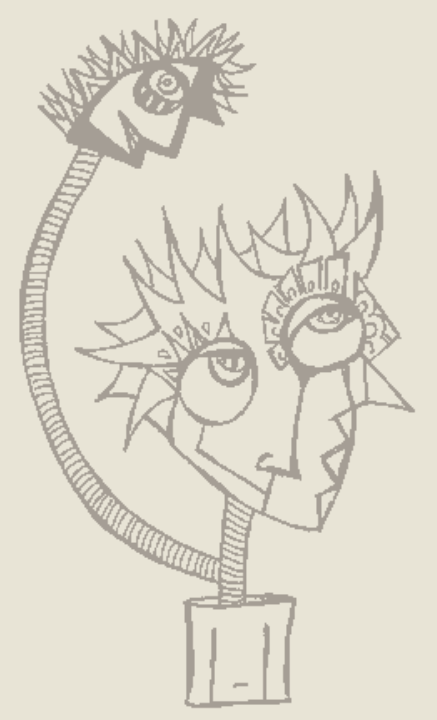

$\mathrm{P}$ rueba de que la Galería de Artes Visuales está creciendo es el incremento de su colección de pinturas, gracias a las donaciones de los pintores que han expuesto en sus salas. La flexibilidad del espacio de la GAV ha permitido que se la pueda usar como sala de conferencias y programar cursos de extensión. Cabe anotar que nuestra galería forma parte de la red de Galerías de Miraflores (MiRa), cosa que ha contribuido a aumentar las visitas guiadas y el flujo de visitantes.

Con el ánimo de celebración hacemos votos por que la GAV y en general la Universidad Ricardo Palma siga desarrollándose a plenitud bajo la guía de nuestro Rector Dr. Iván Rodríguez Chávez, a quien agradecemos por la atención que nos ha dedicado y al Dr. Manuel Pantigoso Pecero, Director de la Oficina Central de Extensión Cultural y Proyección Social por su continua asistencia.

\section{Alfonso Castrillón Vizcarra \\ Artistas y obras}

\section{ARTISTAS Y OBRAS}
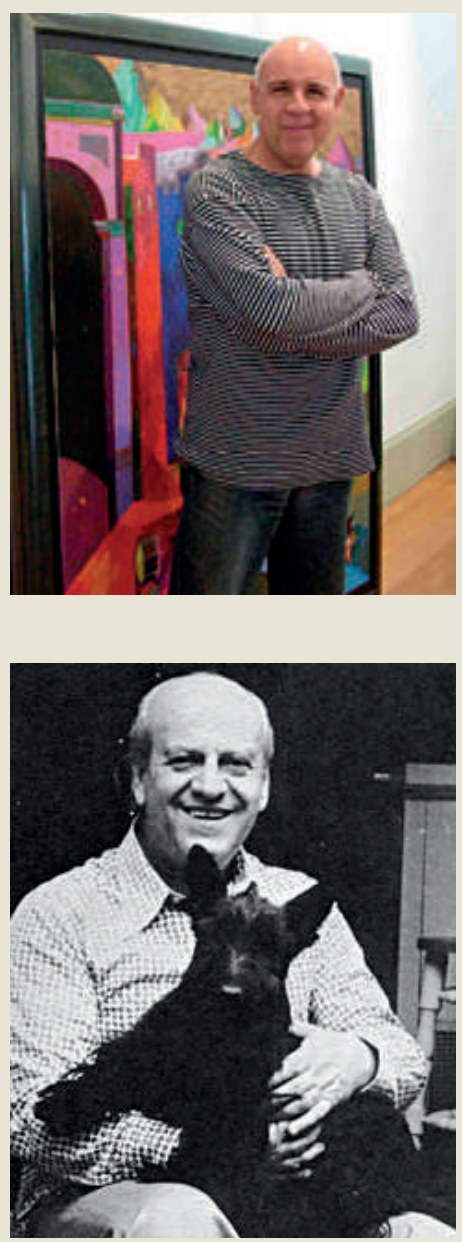

\section{Carlos Enrique Polanco (Lima, 1953)}

Estudió pintura en la Escuela Nacional de Bellas Artes en Lima; realizó estudios de postgrado en el Instituto Central de Artes de Pekín, China; ha participado en muestra colectivas e individuales en el Perú y en el extranjero.

\section{Texto: web.archive.org/web/20080704142514/http://www.agenciaperu.com/cultural/ conversaciones/past/polanco.htm \\ Foto: laseleccioninutil.blogspot.com/2006/08/pinturas-de-polanco-en-el-cc-inca.htm Archivo de la Galería de Artes Visuales.}

\section{Juan Manuel Ugarte Eléspuru (Lima, 1911-2004)}

Cursó estudios e pintura e historia del arte en Argentina, Alemania y Espańa, y fue director durante cerca de tres décadas de la Escuela Pública de Bellas Artes de Perú. Luchó durante todo el tiempo que fue director de la Escuela de Bellas Artes contra los políticos que querían cerrarla para crear la Universidad del Arte en el Perú.

Texto: buscabiografias.com/biografia/verDetalle/9327/Juan\%20Manuel\%20Ugarte\%20 Elespuru

Foto: $\quad$ agendameperu.com/2010/05/10/juan-manuel-ugarte-elespuru-homenaje-al-maestro/ Archivo de la Galería de Artes Visuales.
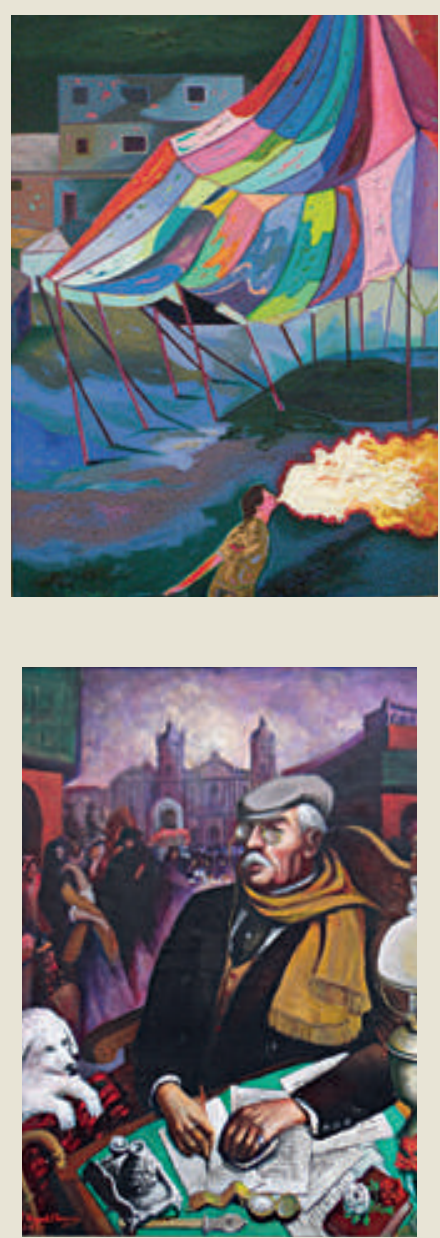

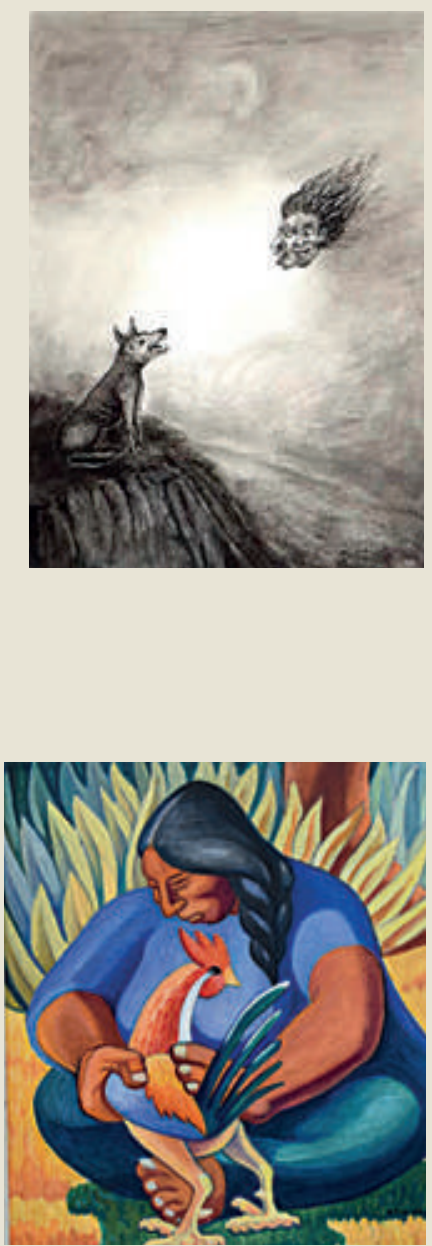

Andrés Zevallos (Cajamarca, 1916 - 2017)

Estudió dibujo y pintura en la Escuela Nacional de Bellas Artes, cuyo director era José Sabogal. En 1965 fue llamado para dirigir la Casa de la Cultura, luego Instituto Nacional de Cultura (INC), cargo al que renunció después de 17 años consecutivos, periodo en el cual realizó importantes obras a favor de la cultura de Cajamarca como lograr la denominación de Cajamarca Patrimonio Histórico y Cultural de las Américas.

Texto: www.librosperuanos.com/autores/autor/5336/Zevallos-de-la-Puente-Andres Fotos: Archivo de la Galería de Artes Visuales.

\section{Regina Silveira (Porto Alegre, 1939)}

Estudió pintura, litografía y xilograbado en 1950. Entre sus profesores se encuentra el pintor brasileńo Iberê Camargo. En los años 70 experimentó con técnicas de grabado y fotocomposición, así como vídeo. En su trabajo, tiene preferencia por los juegos perceptivos y de continuidad en el espacio físico.
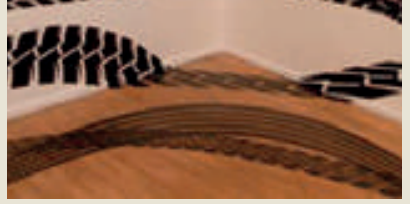

Texto: es.wikipedia.org/wiki/Regina_Silveira

Foto: vogue.globo.com/moda/noticia/2017/08/artista-regina-silveira-assina-joia-para-talento. $\mathrm{html}$ reginasilveira.com

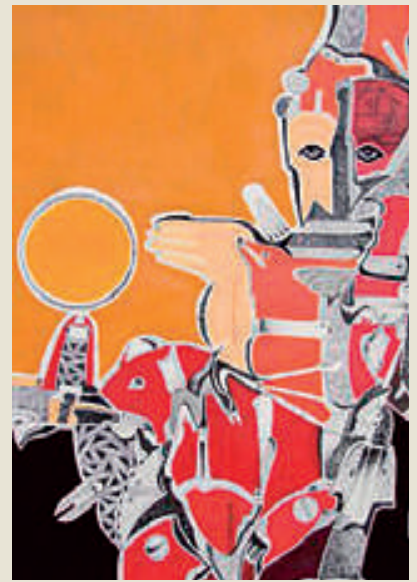

\section{Luis Arias Vera (San Pedro de Lloc, 1932 - Lima, 2016)}

En 1955 fue a Argentina al Taller Rosa Frey y Escuela de Bellas Artes Prilidiano Pueyrredon y Ernesto de la Carcova.

Texto: Archivo de la Galería de Artes Visuales

Foto: $\quad$ AsmatChirinos-Zavala.2013delaRevistalllapaManaTuququkN¹3 Archivo de IIMA
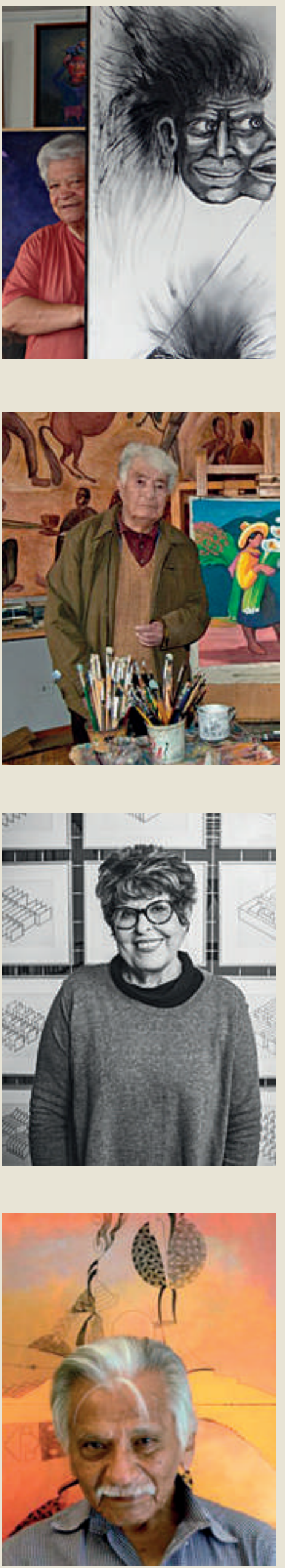

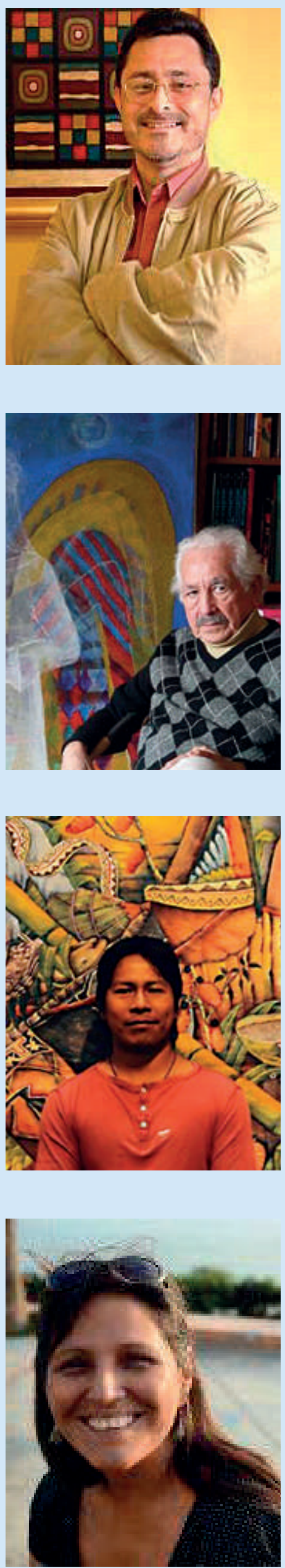

\section{Jhonny Morote (Lima, 1954)}

Comenzó a pintar a los 13 años de edad. Lo abandonó para convertirse en médico y cuanto más profundizó en la ciencia, más fuerte se hizo el llamado de las artes. Artista autodidacta que ha desarrollado un lenguaje visual único y sugerente. Al principio sus pinturas oscilaban entre lo figurativo y lo abstracto; ahora es principalmente abstracto con una fuerte influencia prehispánica.

Texto: Archivo de la Galería de Artes Visuales.

Foto: $\quad$ www.novica.com/artistdetail/?aid $=4064$

Archivo de la Galería de Artes Visuales.

\section{Victor Escalante (Lima, 1937)}

Desde los años 70 se desempeña como diseñador gráfico, pintor, grabador y editor. Se formó en el taller del diseñador gráfico de Markus Barandum, cursó estudios de grabado en la PUCP. Fundó la editorial Arte/Reda (1963). Participó en la III Bienal Americana de Artes gráficas de Colombia (1976). También ha expuesto en Brasil, Francia, Bulgaria y Dinamarca.

\section{Texto: Archivo de la Galería de Artes Visuales. \\ Foto: $\quad$ Archivo del artista.}

Archivo de la Galería de Artes Visuales

\section{Brus Rubio (Loreto, 1984)}

En el 2002 conocio al antropólogo Jürg Gasché quien realizaba un estudio de la cultura Amazónica. Durante sus años con él, empezó a pintar usando tintes naturales y poco tiempo después descubrió su pasión por la pintura como forma de expresar la infinita riqueza de la mitología, la historia y la cultura del pueblo Amazónico.

$\begin{array}{ll}\text { Texto: } & \text { brusrubio.com } \\ \text { Foto: } & \text { deunsilencioajeno.lamula.pe/2016/12/23/brus-rubio-ciudadano-del-mundo/andrea.cabel }\end{array}$ Archivo de la Archivo de la Galería de Artes Visuales.
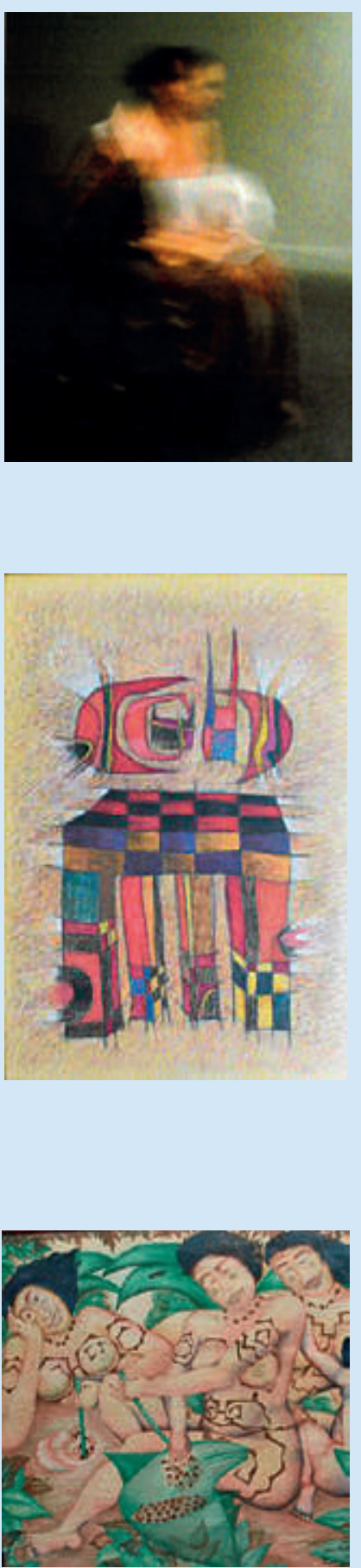

\section{Malú Cabellos (Lima, 1971)}

"Artista visual con formación en Sociología y Fotografía. Licenciada en Sociología por la Universidad Nacional Mayor de San Marcos y graduada en el Master Latinoamericano de Fotografía Contemporánea-Maldefoco 2015 del Centro de la Imagen de Lima. Co-dirige Mamut Art, donde incorpora todas la herramientas del arte para diseñar y desarrollar proyectos publicitarios y sociales."

Texto: malucabellos.pe

Fotos: Archivo de la Galería de Artes Visuales.

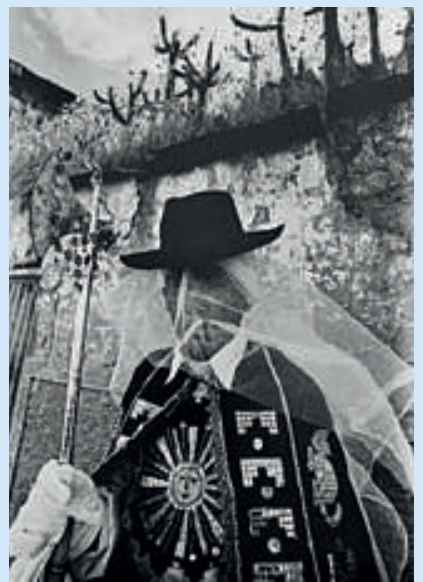




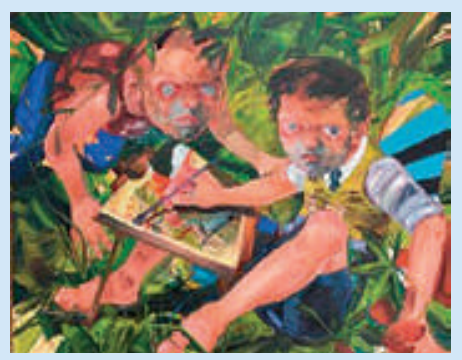

\section{José Luis Carranza (Lima 1981)}

Realiza sus estudios de formación en la Escuela Nacional Superior Autónoma de Bellas Artes del Perú, egresando con la Medalla de Plata, en la especialidad de Dibujo (2004); y la Medalla de Oro, en la especialidad de Pintura (2006). $\begin{array}{ll}\text { Texto: } & \text { enlaceart.com/?CARRANZA-Jose-Luis,316 } \\ \text { Foto: } & \text { cocktail.pe/la-ciencia-de-la-pintura-de-carranza } \\ & \text { Archivo de la Galería de Artes Visuales }\end{array}$

\section{Francisco Olazo Olivera (Cusco, 1904 - 1948)}
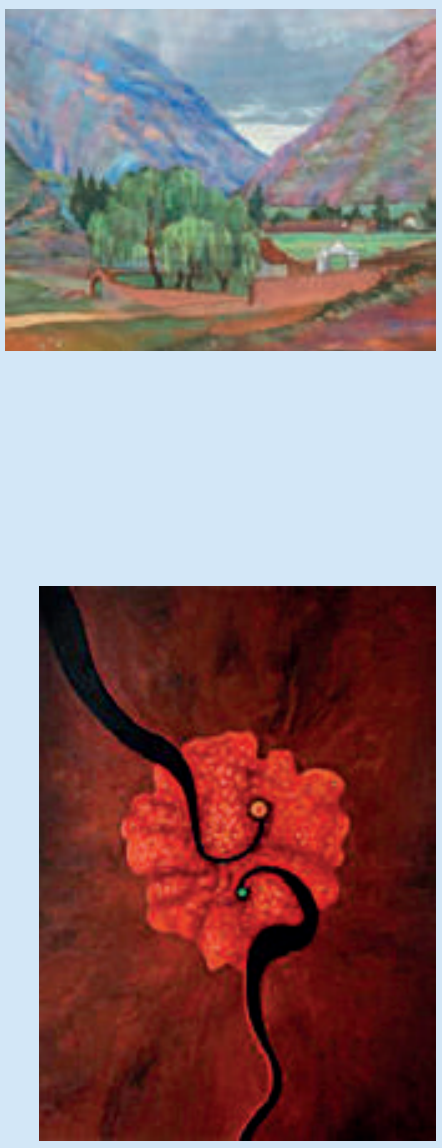

Hijo del escultor Don Ernesto Olazo Allende. "El acuarelista realizó su primera exposición a los 15 años. Recorrió gran parte del altiplano y después viajó a Francia, en donde sus obras recibieron los elogios de la prensa local. Expuso sus pinturas en la galería del reconocido fotógrafo Martín Chambi y fue uno de los fundadores de la Escuela Autónoma de Bellas Artes del Cusco."

Texto: $\quad$ identidadesperuanas.com
Foto: $\quad$ Archivo de la Galería de Artes Visuales.

\section{Maroé Susti}

Licenciada en Bellas Artes y Diseño Gráfico en la Pontificia Universidad Católica. Participa en talleres de dibujo y pintura al óleo en la Liga de Estudiantes de Nueva York, 1983 y 1984. Trabaja en pintura al óleo y acrílico, dibujo, acuarela, collage y cerámica.

Texto: www.maroesusti.com

Foto: $\quad$ De Jose Vera Visagel perteneciente al Archivo de la Galería de Artes Visuales.

\section{Adolfo Asmat Chirinos - Zavala (Puerto Malabrigo, 1966)}

Egresado de la Escuela de Bellas Artes "Macedonio de la Torre" Trujillo, Perú. Estudió en la Facultad de Bellas Artes UCM, Madrid, España 1992. Experto Universitario en Educación Artística, UCM, Madrid, 1999. Promotor Cultural de "Arte Trujillo Contemporáneo”, desde 1992. Ha expuesto en Perú, Ecuador, Bolivia, Colombia, Chile, Canadá, España, México, Estados Unidos,Finlandia, Alemania, Bélgica y Francia.

Texto: artetrujillocontemporaneo.com/adolfo.htm

Foto: Archivo de la Galería de Artes Visuales.
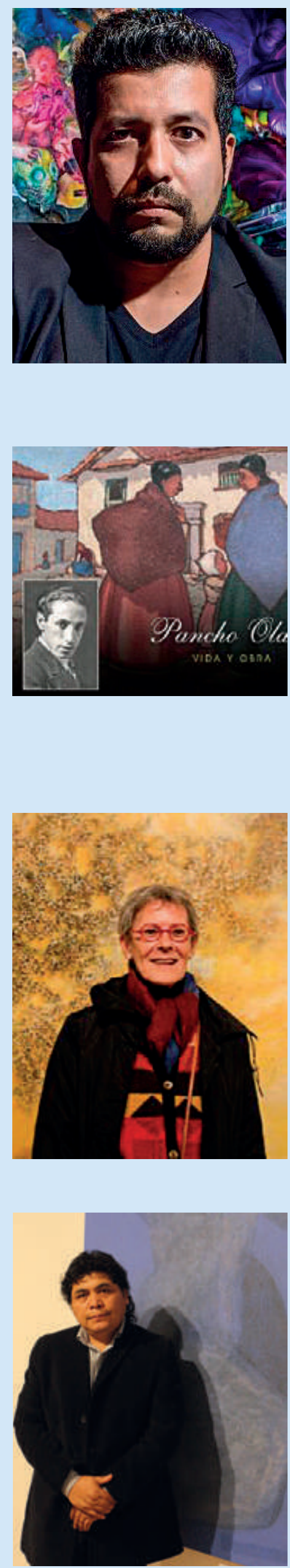


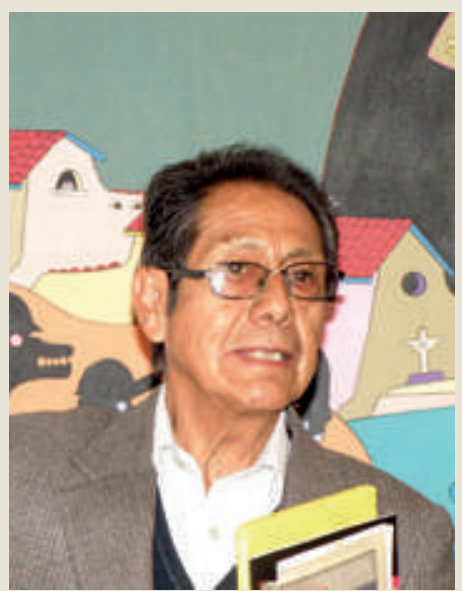

Josué Sánchez (Huancayo 1945)

Es un referente ineludible de la plástica peruana con identidad andina. Con un lenguaje plástico y una iconografía de claros antecedentes prehispánicos, Sánchez ha sabido establecer un diálogo con occidente y reflejar en sus pinturas la esencia pluricultural y mestiza de nuestros Andes. Sus obras, de estilo neofigurativo, bidimensionales y de intensos colores, muestran una estética claramente asentada en el pensamiento holístico andino y recrean el ciclo agrícola, las creencias mágico religiosas, el trabajo y la fiesta, el mundo en las minas y en las aldeas del Amazonas, los mitos y las leyendas.

Texto: www.josuesanchez.pe/biography

Foto: Archivo de la Galería de Artes Visuales.

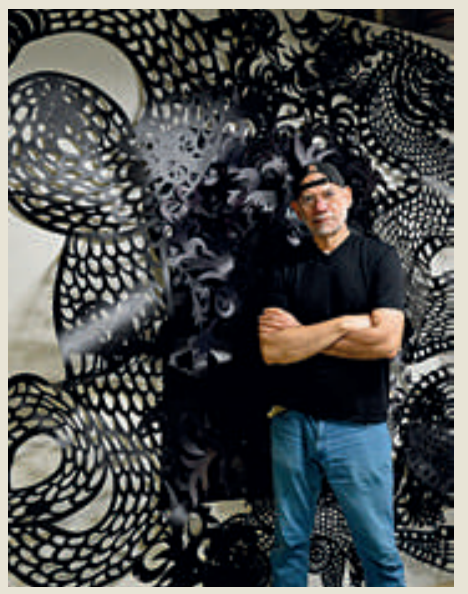

\section{Henry Bermúdez (Maracaibo, 1951)}

Empezó sus estudios de arte entre 1965 y 1970 en la Escuela de Artes Plásticas Julio Arraga de Maracaibo. "Formado como grabador y especializado en litografía, en donde suponemos afianza esa fina línea ornamental que se expande, proliferante, sobre el papel, como la floresta tropical en la que nació y se formó. Henry Bermúdez, confecciona también una suerte de "ensamblaje-collage-mural", formato insólito con el que consigue, sobre todo, monumentalizar la exuberancia gráfica que caracteriza hasta hoy ese lenguaje suyo realizado originalmente con plumilla y tinta china."

Texto: Manuel Munive - 2016 .

Foto: Archivo de la Galería de Artes Visuales.

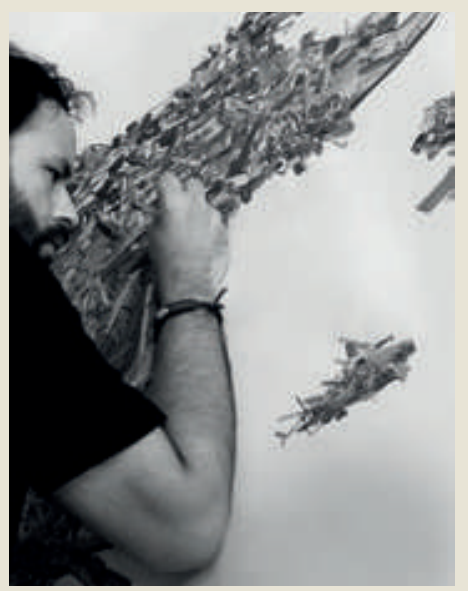

\section{Andrés Ennen (Lima, 1985)}

"Artista, gestor y curador independiente.

Bachiller en artes plásticas con mención en pintura de la Facultad de Arte de la Pontificia Universidad Católica del Perú. Desde antes de finalizar sus estudios en la Facultad de Arte de la Pucp, en el ańo 2009, emprende un proyecto de espacio cultural al que denomina Casa Pausa: espacio no institucional e independiente, el cual viene sirviendo de primera aproximación con la escena para artistas jóvenes y emergentes."

Fuente: Archivo de la Galería de Artes Visuales.

\section{José Carlos Ramos (Huancavelica)}

"Se propone estudiar medicina o arquitectura y durante su preparación académica preuniversitaria recibe la invitación de Carito Belaùnde, hija del Presidente Fernando Belaúnde Terry a exhibir sus trabajos. Al exponer sus pinturas en la residencia de Palacio de Gobierno sus obras son las más elogiadas y uno de los invitados adquiere uno de sus cuadros, lo cual lo decide a emprender el camino del arte. (SIC)." Ingresa a la Escuela de Arte de la Pontificia Universidad Católica del Perú. Donde uno de su profesores es Adolfo Winternitz.

Texto: http://artistajosecarlosramos.com/biografia/bioset.html Foto: $\quad$ Archivo de la Galería de Artes Visuales
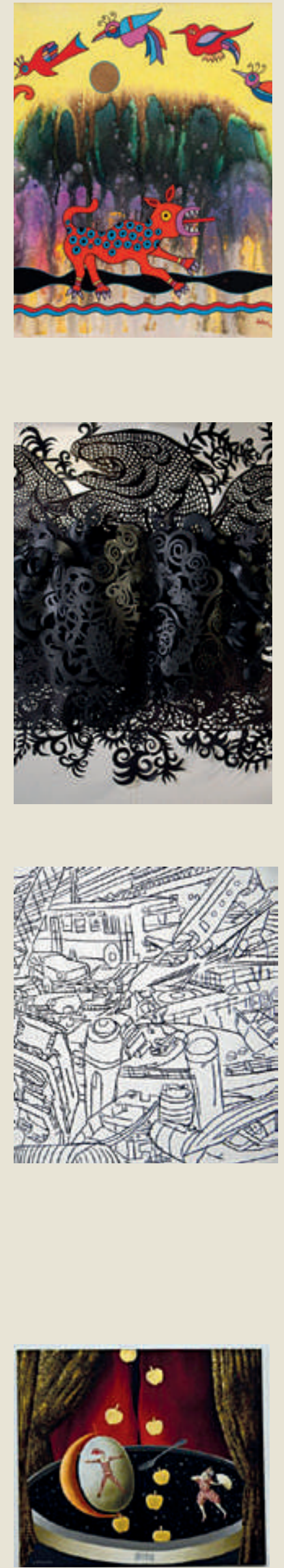

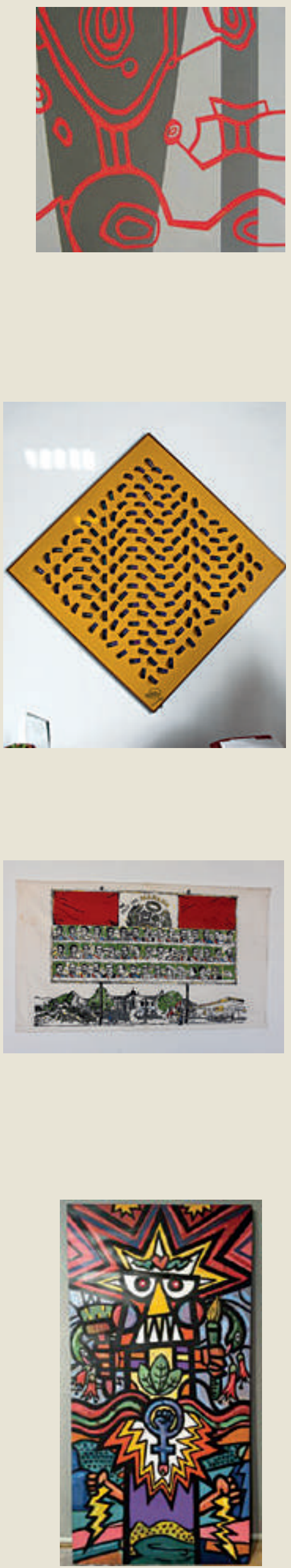

Jesús Ruiz Durand (Huancavelica, 1940)

Matemático, pintor, grabador y diseñador gráfico. Estudió pintura en la Escuela de Bellas Artes del Perú y cine animado en la Universidad de Nueva York. Imparte cátedras de diseńo electrónico, estética contemporánea y estudios culturales. Su obra cinética forma parte de colecciones públicas como el Museo de Arte Moderno de Nueva York y el Museo del Hermitage, Rusia.
Texto: wugaleria.com/es/artistas/artistas-en-colaboracion/jesus-ruiz-durand/
Foto: newslocker.com/es-pe/noticias/noticias-generales/jesuacutes-ruiz-durand-se-estaacute- haciendo-arte-maacutes-banal-e-idiota/

\section{Rosario Noriega (Piura 1957)}

"Más conocida como Charo Noriega, es una artista peruana destacada que formó parte de los colectivos Paréntesis y E. P. S. Huayco. En esta etapa, su producción artística era una herramienta a favor de la crítica social. Además, en retrospectiva, su producción ha tomado como referencia el arte rupestre, prehispánico, la pintura campesina y la iconografía del arte amazónico (Shipibo).”

Texto: es.wikipedia.org/wiki/Rosario Noriega

Foto: Archivo del IIMA

\section{Juan Javier Salazar (Lima 1955 -2016)}

Fue un artista peruano miembro de los colectivos E. P. S. Huayco (1979-1981) y Paréntesis (1979) y muy activo en la producción de arte contemporáneo durante las últimas décadas del siglo XX y las primeras del XXI. Estudió pintura en la Sociedad de Bellas Artes de Lisboa y en la Escuela de Bellas Artes del Perú y arquitectura en la URP.

Texto: es.wikipedia.org/wiki/Juan_Javier_Salazar

Foto: mariacastro.pe/juan-javier-salazar-disidente-venecia/

\section{Elio Martuccelli (Lima, 1968)}

"Participó como estudiante de arquitectura de la Universidad Ricardo Palma en experiencias artísticas con los colectivos Bestias /Bestiario y el Taller NN. También frecuentó por aquellos años el Taller de Escultura de dicha facultad. Acompañó el proceso de creación y formación del grupo de teatro Pataclaun, asociación cultural vigente durante décadas en la escena nacional. Se graduó de arquitecto en 1992. Viajó a España y obtuvo en 1998 el grado de doctor en teoría e historia de la arquitectura por la Escuela Técnica Superior de Arquitectura en la Universidad Politécnica de Madrid en 1998. Ejerce de manera independiente la profesión de arquitecto, como diseńador e investigador.

Fuente: Archivo de la Galería de Artes Visuales.
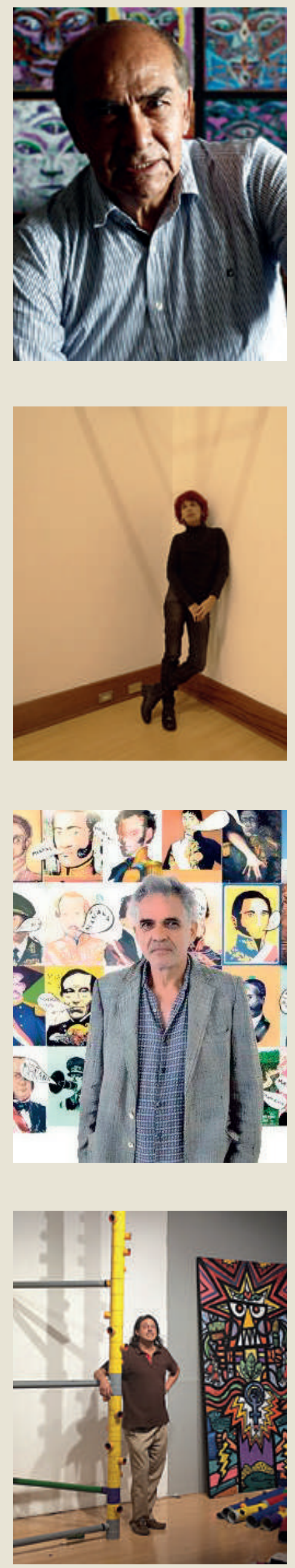

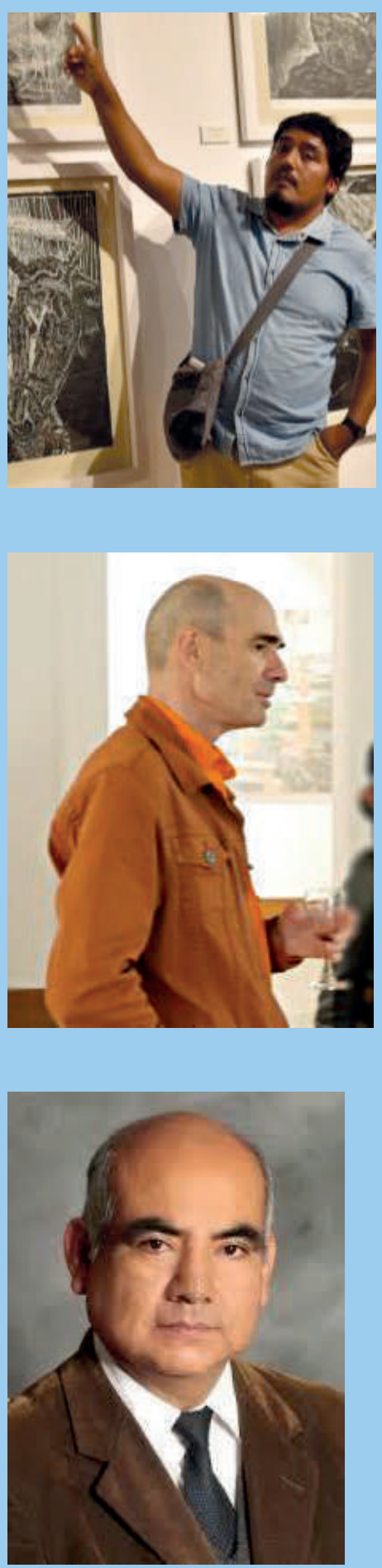

\section{Luis Antonio Torres Villar (Lima, 1984)}

Realizó estudios de Grabado en la Escuela Nacional Superior Autónoma de Bellas Artes del Perú, ENSABAP (2014), ha hecho una residencia artística en el taller del maestro grabador Hugo Besard en Amberes, Bélgica(2010). Cuenta con cinco muestras individuales y con múltiples exposiciones colectivas en el Perú y en el extranjero, Argentina, México, Taiwán, Rumania, Portugal, Polonia, China, Corea, Turquía, España y Japón.

Fuente: Archivo de la Galería de Artes Visuales.

\section{Rv Miloux (París, 1958)}

Desde 2007, vive y trabaja en la ciudad de Iquitos. Ha expuesto individualmente en la galería L'Imaginaire de la Alianza Francesa de Miraflores (2012), en el Museo Amazónico de Iquitos (2010 y 2014), en la galería Art \& Patrimoine de París (1999 - 1992) y en la galería Elston Fine Art de Nueva York (1991), entre otras. Ha participado en más de veinte intervenciones colectivas en Francia, Suiza, Estados Unidos y España.

Texto y fotos: Archivo de la Galería de Artes Visuales.

\section{Mario Caldas (Lima, 1962)}

Licenciado en Ciencias de la Comunicación y Magíster en Educación por la Universidad San Martín de Porres. Tiene estudios de Post-Grado en Pedagogía Universitaria por la Universidad de Lima. Actualmente es Coordinador de las actividades Artisticas y culturales de la oficina central de extensión universitaria y proyección social.

Fuente: Tradición $\mathrm{N}^{\circ} 11$
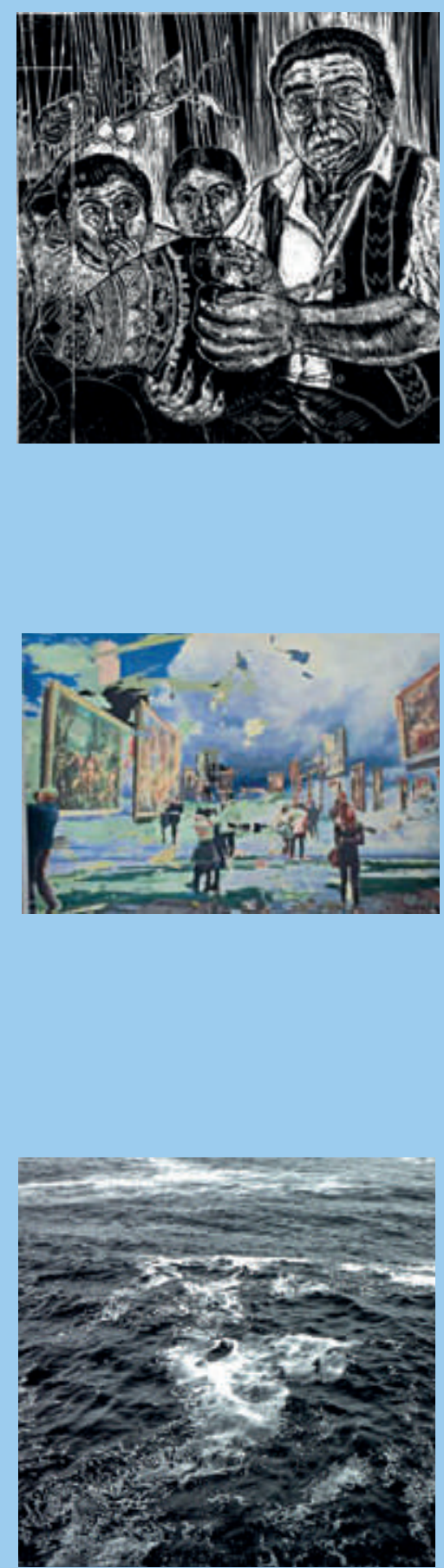

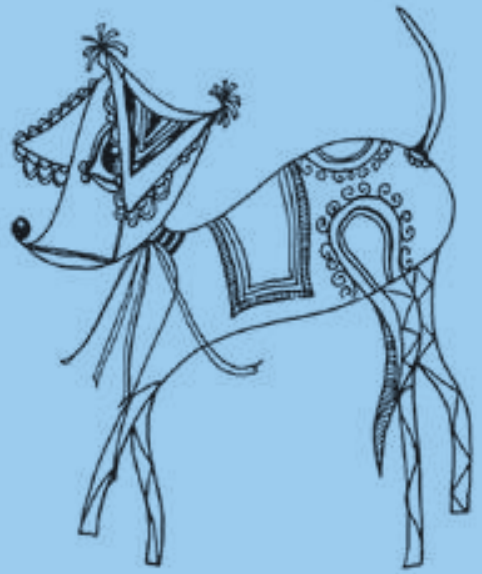

